\title{
Menstrual hygiene: knowledge and practice among adolescent school girls in rural settings
}

\author{
Gitanjali Kapoor $^{1 *}$, Dinesh Kumar ${ }^{2}$
}

\author{
${ }^{1} \mathrm{~J} \&$ K Health Services, Jammu, Jammu and Kashmir, India \\ ${ }^{2}$ Department of Obstetrics and Gynecology, SMGS Hospital, GMC, Jammu, Jammu and Kashmir, India
}

Received: 22 December 2016

Accepted: 31 January 2017

\author{
*Correspondence: \\ Dr. Gitanjali Kapoor, \\ E-mail: highcourtnaresh@gmail.com
}

Copyright: $(\odot$ the author(s), publisher and licensee Medip Academy. This is an open-access article distributed under the terms of the Creative Commons Attribution Non-Commercial License, which permits unrestricted non-commercial use, distribution, and reproduction in any medium, provided the original work is properly cited.

\section{ABSTRACT}

Background: Menstrual hygiene is an issue that every girl and women must deal within her life, but there is lack of awareness on the process of menstruation and proper requirements for managing menstruation among adolescent girls. The objectives of present study are to assess the knowledge and the practices of menstrual hygiene among the rural school going adolescent girls and to assess the restrictions practiced by adolescent school going girls during menstruation.

Methods: It was a community based cross-sectional study. The present study was undertaken among the adolescent school going girls in the Govt. Higher Secondary School in Marh block of Jammu district. 132 girls of the 8th, 9th, 10th, 11th and 12th standard of the school was selected for the study. A predesigned, pretested and structured questionnaire was used in the study. The data collection technique was a personnel interview of the study subjects.

Results: The mean age of menarche in the study subjects was 13.43 years. It was evident that only $65(49.24 \%)$ of the participants were aware about menstruation before menarche and the most important source of the information about menstruation for them was found to be their mothers. 59.09\% girls used sanitary pads only, $27.27 \%$ used new cloth and $13.64 \%$ used old washed cloth. $98.48 \%$ of the respondents followed some restriction or taboo during menstruation. $93.18 \%$ had daily bath. Regular hand washing was present in $90.91 \%$ subjects of which $86.36 \%$ subjects used soap and water for hand washing. Regular cleaning of the external genitalia was present in $65.91 \%$ subjects only, of which $66.67 \%$ used soap and water and $33.33 \%$ used only water.

Conclusions: There is a need to educate the girls about menstruation, its importance and hygiene maintenance; to enable them to lead a healthy reproductive life in future.

Keywords: Adolescent girls, Menarche, Menstruation, Menstrual hygiene, Practices

\section{INTRODUCTION}

Menstrual hygiene is an issue that every girl and women has to deal with in her life, but there is lack of awareness on the process of menstruation and proper requirements for managing menstruation among adolescent girls. Menstruation is generally considered as unclean in the Indian society especially in rural settings. Isolation of the menstruating girls and restrictions being imposed on them in the family have reinforced a negative attitude towards this phenomenon. ${ }^{1}$ Issues associated with menstruation are never discussed openly and this burdens young girls by keeping them ignorant of this biological function..$^{2-4}$ Even after the attainment of menarche, very little information is given to young girls about the physiological processes involved and the hygienic practices to be followed, the lack of which sometimes result into adverse health outcomes like reproductive tract infection, UTIs etc. ${ }^{5-9}$ Menstruation hygiene is an issue that has not received adequate attention in the reproductive health and water, sanitation and hygiene (WASH) sectors in developing countries like India and its 
relationship with and impact on achieving many millennium development goals (MDGs) is rarely acknowledged. ${ }^{10-12}$ Very few studies have included the detailed aspects of the menstrual practices among adolescent girls in rural areas. It was therefore considered as relevant to investigate the menstruation related knowledge and practices among the school going adolescent girls in rural India. The data about their level of knowledge and the practices which are followed by them with respect to menstruation are beneficial for planning a program for improving the awareness level with respect to their life processes and promoting their quality of life. Hence, the present cross-sectional study was carried out.

\section{METHODS}

It was a community based cross-sectional study. The present study was under taken among the adolescent school going girls in the Govt. Higher Secondary School in Marh block of Jammu district. 132 girls of the 8th, 9th, 10th, 11th and 12th standard of the school was selected for the study. A predesigned, pretested and structured questionnaire was used in the study. The data collection technique was a personnel interview of the study subjects. After taking permission from the school authorities, the students were explained the purpose of the study, a rapport was built up with girl students and their verbal consents were obtained. The purpose of the study and the nature of the information which had to be furnished by the study subjects were explained to them.

\section{RESULTS}

Table 1 ( $a$ and $b$ ) presents the demographic details of the study subjects. It was evident that the mean age of the study subjects who were studied was $15.71 \pm 1.28$ years, while their age range was from 12-18 years. A majority of the mothers of the study girls were illiterate $(36.36 \%)$.

The Table 2 reveals that the mean age of menarche in the study subjects was $13.43 \pm .83$ years. It was evident that only $65(49.24 \%)$ of the participants were aware about menstruation before menarche and the most important source of the information were mothers $43(66.15 \%)$ followed by sisters $14(21.55 \%)$, friends $4(6.16 \%)$, Teachers $2(3.07 \%)$ and relative $2(3.07 \%)$.

Table 1a: Demographic characteristics of the study subject $(\mathrm{N}=132)$.

\begin{tabular}{|l|l|l|}
\hline $\begin{array}{l}\text { Characteristics } \\
\text { Age in years }\end{array}$ & No. & Percentage \\
\hline 12 & 1 & 0.76 \\
\hline 13 & 5 & 3.79 \\
\hline 14 & 17 & 12.88 \\
\hline 15 & 29 & 21.97 \\
\hline 16 & 46 & 34.85 \\
\hline 17 & 23 & 17.42 \\
\hline 18 & 11 & 8.33 \\
\hline
\end{tabular}

Table 1b: Demographic characteristics of the study subject $(\mathbf{N}=132)$.

\begin{tabular}{|c|c|c|}
\hline Characteristics & No. & Percentage \\
\hline \multicolumn{3}{|c|}{ Education of mother } \\
\hline Illiterate & 48 & 36.36 \\
\hline Primary & 11 & 8.33 \\
\hline Middle & 40 & 30.33 \\
\hline Secondary & 31 & 23.48 \\
\hline Higher Secondary & 02 & 1.51 \\
\hline
\end{tabular}

Table 2: Information about menarche.

\begin{tabular}{|c|c|c|}
\hline Variable & No. & Percentage \\
\hline \multicolumn{3}{|l|}{ Age of menarche } \\
\hline$\leq 11$ & 03 & 2.28 \\
\hline 12 & 10 & 7.58 \\
\hline 13 & 52 & 39.39 \\
\hline 14 & 61 & 46.21 \\
\hline$\geq 15$ & 06 & 4.54 \\
\hline $\begin{array}{l}\text { Awareness about } \\
\text { menstruation before } \\
\text { menarche }\end{array}$ & 65 & 49.24 \\
\hline \multicolumn{3}{|c|}{ Sources of information before menarche } \\
\hline Mother & 43 & 66.15 \\
\hline Sister & 14 & 21.55 \\
\hline Friend & 04 & 6.16 \\
\hline Teacher & 02 & 3.07 \\
\hline Relative & 02 & 3.07 \\
\hline
\end{tabular}

Table 3 reveals that the study on the practices during menstruation showed that $78(59.09 \%)$ girls used sanitary pads only, $36(27.27 \%)$ used new cloth and 18 (13.64\%) used old washed cloth.

Table 3: Distribution of subjects according to their practice during menstruation.

\begin{tabular}{|c|c|c|}
\hline Attributes & No. & Percentage \\
\hline \multicolumn{3}{|l|}{ Type of absorbent $(\mathrm{N}=132)$} \\
\hline Sanitary Pads & 78 & 59.09 \\
\hline New Cloth & 09 & 6.82 \\
\hline Old Washed Cloth & 10 & 7.58 \\
\hline $\mathrm{Pad}+\mathrm{New}$ Cloth & 27 & 6.06 \\
\hline Pad + Old Washed Cloth & 08 & 20.45 \\
\hline \multicolumn{3}{|c|}{ Reasons for not using pads $(\mathrm{N}=19)$} \\
\hline High Cost & 15 & 78.94 \\
\hline Not Available & 02 & 10.53 \\
\hline Disposal Problem & 02 & 10.53 \\
\hline \multicolumn{3}{|c|}{$\begin{array}{l}\text { Problems faced while using old washed cloth during } \\
\text { washing and drawing }(\mathrm{N}=18)\end{array}$} \\
\hline Yes & 15 & 83.33 \\
\hline No & 03 & 16.67 \\
\hline
\end{tabular}

Type of problem faced while using old washed cloth during washing and drawing $(\mathrm{N}=15)$

\begin{tabular}{|l|l|l|}
\hline Shortage of water & 06 & 40 \\
\hline Scarcity of place & 03 & 20 \\
\hline Lack of privacy & 06 & 40
\end{tabular}


Out of the 18 patients who used old washed cloth during menstruation, $15(83.33 \%)$ had problem while washing and drying of the cloth which consisted of shortage of water $(40 \%)$, lack of privacy $(40 \%)$ and scarcity of place (20\%). $98.48 \%$ of the respondents followed some restriction or taboo during menstruation (Table 4).

Table 4: Restriction practiced during menstruation.

\begin{tabular}{|l|l|l|}
\hline Restricted practiced** & No. & Percentage \\
\hline Attend religious functions & 67 & 51.54 \\
\hline Routine Household Work & 45 & 34.62 \\
\hline Playing & 13 & 10 \\
\hline Attending School & 37 & 28.46 \\
\hline Certain types of food & 31 & 23.85 \\
\hline *Multiple response & & \\
\hline
\end{tabular}

Table 5: Distribution of subjects according to their hygienic practices during menstruation.

\begin{tabular}{|c|c|c|}
\hline $\begin{array}{l}\text { Hygienic practices during } \\
\text { menstruation }\end{array}$ & No. & Percentage \\
\hline \multicolumn{3}{|l|}{ Daily bath } \\
\hline Yes & 123 & 93.18 \\
\hline No & 09 & 6.82 \\
\hline \multicolumn{3}{|l|}{ Hand washing } \\
\hline Regular* & 120 & 90.91 \\
\hline Irregular & 12 & 9.09 \\
\hline \multicolumn{3}{|l|}{ Hand washing with } \\
\hline Water only & 04 & 3.03 \\
\hline Soap and water & 114 & 86.36 \\
\hline Water and antiseptic & 14 & 10.61 \\
\hline \multicolumn{3}{|c|}{ Cleansing of external genitalia } \\
\hline Regular $^{* *}$ & 87 & 65.91 \\
\hline Irregular & 45 & 34.09 \\
\hline \multicolumn{3}{|c|}{ Cleaning of external genitalia with } \\
\hline Water only & 44 & 33.33 \\
\hline Soap + Water & 88 & 66.67 \\
\hline \multicolumn{3}{|l|}{ Method of disposal } \\
\hline Burn it & 10 & 7.58 \\
\hline Throw it routine waste & 93 & 70.45 \\
\hline $\begin{array}{l}\text { Others (Don't } \\
\text { Dispose/flush/hide) }\end{array}$ & 29 & 21.97 \\
\hline \multicolumn{3}{|l|}{ Toilet facility } \\
\hline Yes & 101 & 76.52 \\
\hline No & 31 & 23.48 \\
\hline
\end{tabular}

*Regular: hand washing every time after visit to the toilet during menstruation; ${ }^{* *}$ Regular: Frequency of cleaning of external genitalia is $\geq 2 /$ day.

Table 5 reveals that among hygienic practices during menstruation, $93.18 \%$ had daily bath. Regular hand washing was present in $90.91 \%$ subjects, of which $86.36 \%$ subjects used soap and water for hand washing, $10.61 \%$ used water and antiseptics and $3.03 \%$ used water only. Regular cleaning of the external genitalia was present in $65.91 \%$ subjects only, of which $66.67 \%$ used soap and water and $33.33 \%$ used only water. Toilet facility was present in homes of $76.52 \%$ subjects and $23.48 \%$ subjects' homes were still deprived of toilet facility. $70.45 \%$ of the subjects were disposing the materials used during menstruation by throwing that in routine waste, $7.58 \%$ were burning it and $21.97 \%$ were using other methods.

\section{DISCUSSION}

In the present study, the mean age of menarche of the study subjects was $13.43 \pm .83$ years which is similar to studies conducted by Bhattacharyya $\mathrm{M}$ et al and Thakre $\mathrm{SB}$ et al in which the mean age of menarche was found out to be 13.2 years and 12.86 years respectively. ${ }^{13,14}$ Prior awareness regarding menarche and menstruation among girls is generally low in rural areas in our country. It was evident that $50.76 \%$ of the subjects were ignorant about menstruation before menarche in the study. This in accordance to study by Bhattacharyya $\mathrm{M}$ et al in which $58 \%$ of adolescent girls were lacking knowledge of menstruation before menarche. ${ }^{13}$ The main source of information of menstruation before menarche in present study was mothers of the girls $(66.15 \%)$ followed by sisters $(21.55 \%)$. This is similar to the study done by Thakre SB et al in which mothers were the main informant followed by sisters in $71.33 \%$ and $23.78 \%$ girls respectively. ${ }^{14}$ Menarche is an important event in girls at the threshold of adolescence and ideally, mothers should be the main informants at this tender age of the girls. But the high level of ignorance on the part of this study subjects was due to low level of education of their mothers. In present study, 59.09\% of the girls used sanitary pads only where as $40.91 \%$ used either cloth (new or old) alone or in combination with sanitary pads. This in accordance to the investigations of Bhattacharyya $M$ et al in which $81.73 \%$ of the girls used sanitary pads only where as $18.27 \%$ used either cloth (new or old) alone or in combination with sanitary pads. In this study although only $13.64 \%$ used old washed cloth, $83.33 \%$ of them faced problems during washing and drying in the form lack of place, water and privacy. ${ }^{13}$ This is similar to study by Yasmin S et al in which $15.7 \%$ used old washed cloth and $70 \%$ of them faced problems during washing and drying in the form lack of place, water and privacy. ${ }^{12}$ This is really cause of concern because shortage of water leads to improper washing of cloth and lack of place and privacy leads to storage of these in unhygienic places which is invitation to infectious organisms. ${ }^{15}$ The main reason for not using pads in present study was nonaffordability due to high $\operatorname{cost}(78.94 \%)$ followed by nonavailability and disposal problems which is similar to study by Thakre SB et al. ${ }^{14}$ Different restrictions were practiced by most of the girls in the present study, possibly due to the different rituals in their communities; the same were running in their families for years long, being practiced by their mothers or their grandmothers, due to lack of knowledge about menstruation. These findings were consistent with other studies. ${ }^{5,16,17}$ The present study showed that $93.18 \%$ girls took daily bath 
during menstruation which is similar to study by Bhattacharyya $\mathrm{M}$ et al in which $86.08 \%$ girls took daily bath. Regular hand washing was present in $90.91 \%$ girls, $86.36 \%$ of which used soap and water where as in study by Bhattacharyya $\mathrm{M}$ et al $63.04 \%$ used soap and water for hand washing. ${ }^{13}$ Regular cleaning of external genitalia was present in only $65.91 \%$ girls out of which only $66.67 \%$ used soap and water for cleaning. Studies by Bhattacharyya $M$ et al and Thakre SB et al showed $64.78 \%$ and $56.16 \%$ girls used soap and water for cleaning of external genitalia respectively whereas study by Dasgupta A et al reported that $97.5 \%$ rural adolescent girls used soap and water for cleaning of external genitalia. ${ }^{13,14,16}$ The reason for lesser number of girls cleaning the external gentilala was lack of knowledge about menstrual hygiene and lack of privacy.

\section{CONCLUSION}

The current study has highlighted the needs of the adolescent girls to have accurate and adequate information about menstruation and its appropriate management. Mothers are the first teacher of the children, so they need to be equipped with the correct information as well as communication skills, so that adolescent girls are ready for this important physiological event in their life.

\section{Funding: No funding sources}

Conflict of interest: None declared

Ethical approval: The study was approved by the Institutional Ethics Committee

\section{REFERENCES}

1. Dhingra R, Kumar A. Knowledge and practices related to menstruation among tribal (Gujjar) adolescent girls. Etho-Med. 2009;3(1):43-8.

2. Ahuja A, Tiwari S. Awareness about pubertal changes among adolescent girls. J Fam Welf. 1995;41(1):46-50.

3. Chaudhari RH. Socio-economic demographic and reproductive health profile of adolescents in the SAARC countries. Paper presented in south Asia Conference on Adolescents. 1998; New Delhi, India.

4. Khanna A, Goyal RS, Bhawsar R. Menstural practices and reproductive problems: A study of adolescent girls in Rajasthan. J Health Manag. 2005;7(1):91-7.

5. Mudey AB, Keshwani N, Mudey GA, Goyal RC. A cross-sectional study on the awareness regarding safe and hygienic practices amongst school going adolescent girls in the rural areas of Wardha district. Glob J Health Sci. 2010;2(2):225.
6. Bhatia JC, Cleland J. Self reported symptoms of gynecological morbidity and their treatment in South India. Stud Fam Plann. 1995;26:491-5.

7. Jugal R, Kandpal SD, Semwal J.Social aspects of menstruation related practices in adolescent girls of district Dehradun. Ind $\mathbf{J}$ of community health 2013;25(3);213-16.

8. Mensch BS, Bruce J, Greene ME. The uncharted passage:Girls' adolescence in the developing world[internet]1999. Available www.popcouncil.org. Cited 21 jan 2017.

9. Singh MM, Devi R, Garg S, Mehra M. Effectiveness of syndromic approach in management of reproductive tract infections in women. Indian $\mathrm{J}$ Med Sci. 2001;55(4):209-14.

10. Ten VTA. Menstrual hygiene: A neglected condition for the achievement of millenium development goals[internet]2007.Available at mwia.net/wpcontent/uploads/2012/12/menstrual- hygiene.pdf. cited 21 jan 2017.

11. Menstrual hygiene in South Asia: A neglected issue for WASH Programmes [internet]. Available at www.wateraid.org/ /media/publications/menstrualhygiene-south-asia.pdf.

12. Yasmin S, Manna N, Mallik S, Ahmed A, Paria B. Menstrual hygiene among adolescent school students: An indepth cross-sectional study in an urban community of West Bengal, Ind J Dent Med Sci. 2013;5(6):22-6.

13. Bhattacharyya M, Sen P, Hazra S, Sinha RN, Sahoo S. A Study of Menstrual Hygiene among Adolescent school girls in a slum area of Kolkata. Ntl $\mathrm{J}$ of Community Med. 2015;6(3):345-8.

14. Thakre SB, Thakre SS, Reddy M, Rathi N, Pathak K, Ughade S. Menstrual Hygiene: Knowledge and practice among adolescent school girls of Saoner, Nagpur district. J Clinic Diag Res. 2011;5(5):102733.

15. EL Gilany A, Badwi K, EI. Fedawy S. Menstrual hygiene among adolescent girls in Mansoura, Egypt. Reprod Health Matt. 2005;13(26):147-52.

16. Dasgupta A, Sarkar M. Menstrual Hygiene: How Hygienic is the Adolescent Girl. Ind J Commun Med. 2008;33(2):77-80.

17. Narayan KA, Shrivastava DK, Pelto PJ, Veerapmmal S. Puberty rituals, reproductive and health of adolescent school girls of South India. Asian-Pac Popul J. 2001;16:225-38.

Cite this article as: Kapoor G, Kumar D. Menstrual hygiene: knowledge and practice among adolescent school girls in rural settings. Int J Reprod Contracept Obstet Gynecol 2017;6:959-62. 